\title{
Medicine in Old Age
}

\section{Care of the Elderly in General Practice}

\author{
CHARLES HODES
}

British Medical fournal, 1973, 4, 41-42

By mid 1971 the population of the retirement ages -65 years and over, men and women-had increased by $15 \%$ since 1961 . By 1981 this population will have risen again by a similar amount ${ }^{1}$ The average list size per general practitioner is now about 2,500 and therefore he provides general medical services for 300 patients over 65 years of age, with about 100 of these being over 75. The development of the health team ${ }^{2}$ in recent years has enabled the general practitioner to approach the care of the elderly more from the point of view of prevention and early diagnosis, ${ }^{3}{ }^{4}$ and new developments with social workers in general practice ${ }^{5}$ may bring further benefits.

The assessment of the patient's needs and the organization of the care required are the essential tasks of the general practitioner. These needs may be known or unknown to the patient. At least six different aspects should be considered.

\section{The Primary Care Team}

The general practitioner, the health visitor, and the district nurse together can provide the best care for the elderly in their own home. Working from a common centre and sharing one medical record, there is adequate opportunity for exchange of information-which is so important in giving personal medical care to patients who often have some degree of mental confusion, in addition to the usual spectrum of diseases. Age is not a barrier to attendance at the surgery, and in fact the elderly patient should be encouraged to remain mobile and attend as required. Consultation with the health visitor and treatment by the district nurse should also be available at the surgery. Appointmentsmaking and keeping - are easily overlooked by the elderly and it helps if they are always given an appointment in writing and a sympathetic receptionist fits them in without too much waiting if an appointment has not been made. Though willing relatives and friends may help increasingly with their own cars, more organized transport services ${ }^{6}$ in general practice are required if the preventive approach is to increase.

Information about the services available locally should be kept at every practice. Local authorities often have booklets of services and can provide well-illustrated pamphlets on such subjects as diet and exercise; the health visitor is of course the best person to give out this information and can supplement it with individual consultation and with patient groups. Group discussions are also helpful in preparing for retirement ${ }^{7}$, and health education in the elderly should also be concerned with the prevention of accidents and fire safety. Local clubs, laundry ser-

Theobald Centre, Boreham Wood, Herts, WD6 4PU

CHARLES HODES, M.B., M.R.C.G.P., General Practitioner

vices, washing facilities, chiropody, and meals-on-wheels are generally available and should be introduced to patients even if only required occasionally. Convalescent holidays are especially worthwhile in the elderly and whenever possible should include both husband and wife.

\section{NURSES' ROLE}

The nurse has been identified more with the care of the elderly sick patient. She can be supported in her work in the home by bath attendants and male nurses, who are playing an increasingly important part in the care of the male geriatric patient. Night nursing may also be available and if required only for a short time can make hospital admission unnecessary. Visits to the home for routine injections can be used as a method of surveillance and any change can be reported to other members of the team.

At present there is little in the way of domiciliary physiotherapy but the district nurse can give help with breathing exercises for the chest infection and continuing support for the patient with a hemiplegia. Aids to nursing - such as commodes, bed rests, and disposable bedding supplies - are always available. Laboratory services are now used extensively by general practitioners, and the district nurse can take urine and blood specimens in the home and return them to the surgery for collection by the hospital transport services. For haemoglobin estimation a Spence Haemoglobinometer is very simple and quick to use, in both the home and surgery, and when any anaemia is due to poor diet the health visitor can soon call at home with advice and help.

\section{PRACTICE PREMISES}

Practice premises have changed considerably in recent years and very large centres may present problems for the older patient. Cars should be able to drive up to the front entrance of the building, the doors should be wide enough for a wheelchair, and preferably there should be no steps. When all the members of the team have their own accommodation in the building referral is simpler and joint consultation can deal with problems quickly. A sufficient number of warm examination rooms allow the patients to dress and undress at their usual speed, and they can be helped by a receptionist or nurse; this also permits the general practitioner to carry on with other duties.

Good communication is facilitated by regular meetings between members of the primary care team. A high standard of record keeping is important and the problem-orientated record ${ }^{8}$ may be found useful in geriatric care. All patients should keep with them at all times a treatment card, which can be used for repeat prescriptions and give useful information to any doctor seeing the patient as an emergency without the medical record being available.

Studies on the unreported needs of old people ${ }^{\circ}$ and an evaluation of early diagnostic services for the elderly ${ }^{10}$ have 
indicated the need for preventive care. To carry this out in general practice requires an age-sex register from which the geriatric register can be constructed.11 12 Invitations for examinations can be sent to selected patients, and these screening examinations can be carried out by the primary care team in the surgery and in the home; treatment and follow-up are carried out as required. Special registers for high-risk groups, such as patients living alone and the surviving partner on the death of a spouse, are indicated.

\section{Social Services}

The elderly patient depends on the social services as well as the primary medical care team to live in the community. The social worker's client and the general practitioner's patient are the same person, and working together can only improve the total care of the elderly. If the social worker can use the general practitioner's premises, regular communication is more likely and the preventive approach possible. The many benefits now available in the way of financial help and housing are best dealt with by the social worker. Psychogeriatric cases need the support of the social work services and patients recently discharged from hospital can be followed by a worker who is in close contact with the psychiatric services. The home help, in addition to cleaning and shopping duties, is a great support for the often depressed and isolated patient, and can alert the general practitioner if there is any deterioration.

When the elderly patient can no longer manage at home, the social worker will arrange alternative accommodation. This may be in a flat or bungalow with a supervising warden. If this is not sufficient, residential accommodation can be provided on a temporary or permanent basis. The temporary care may be used when a relative has to go into hospital or goes off on holiday; it may also be used for day care when meals are provided and occupational therapy is available. This also relieves the isolation of the permanent residents, bringing them into contact with their community, and introduces the temporary residents to what might become their home.

By arrangement with the local authority, the general practitioner may provide medical care for the residents. In this work he can be supported by the health visitor and district nurse. It is useful to have an assessment chart for patients in addition to the usual medical records, which can be shared by the primary medical care team. The chart is used to record essential information about the patients, and to note changes which occur with time. The first part can be completed by the health visitor, and gives a score based on assessments of physical state, mental state, activity, mobility, and incontinence. If the score rises, the patient is deteriorating. The second part is completed by the nurse on admission and then periodically as indicated; there is a scoring. system for hearing and the state of the feet.

\section{Medical Services}

The geriatrician and his social worker in the local hospital are now very much part of community care and should be well known by the general practitioner. Domiciliary visits should be readily available without undue delay and requested for assessment and opinion, not only for admission. This prevents crisis from developing and allows the geriatrician to plan his admissions. The increase in the numbers of psychogeriatric patients in general practice gives rise to problems of regular medication and also to over-dosage; close supervision is required of patients living alone. The inclusion of geriatric and psychiatric services in new district hospitals will strengthen the support given to general practitioners.

Refractive errors are common and old spectacles may have been worn for many years; simple tests for visual acuity can be done in general practice but the detection of glaucoma requires special equipment and should be carried out by an ophthalmologist. During school holidays a technician with suitable equipment may be "borrowed" from the local authority for sight testing in old people's homes. Hearing aids are usually given out by special centres and often involve further travel for examination and fitting; patients of any age may benefit by an aid and there should be regular supervision of its use and performance.

\section{The Community}

The elderly patient usually wishes to continue to be independent and is supported by family and neighbours. The general practitioner can help by providing and introducing skilled help. The voluntary societies such as the British Red Cross and W.R.V.S. and help given by local groups such as Rotary are most valuable. Group practices and health centres can have groups of "friends," who give help of all kinds to the elderly.

\section{The Patient}

Old people often do not come forward for care-medical and social. This reluctance may be less in relation to the family doctor who is a familiar face, and the health visitor and nurse working with him are identified by the patient as part of the same care. An understanding of the patient's attitude is therefore important, and a health education programme can be introduced which promotes early diagnosis and the acceptability of any treatment offered. When an elderly patient is dying at home the primary care team needs all its skills. They can offer complete care when the patient may need them most and can continue to support the bereaved.

\section{The Future}

The identification of the elderly in general practice is essential for a preventive programme, and it is to be hoped that executive councils will provide geriatric age-sex registers as a regular service. They may, of course, come within the province of the district community physician in 1974, and perhaps he will also supply the transport for patients which will facilitate better care. Easier communication by provision of more telephones is needed. The provision of more day centres and day hospitals will enable the care of the elderly in general practice to continue at a high standard.

\section{References}

${ }^{1}$ Department of Health and Social Security, On the State of the Public Health. London, H.M.S.O., 1971.

2 Royal College of General Practitioners, Present State and Future Needs of General Practice, 3rd edn. London, Royal College of General Practitioners, 1973.

${ }^{3}$ Hodes, C., Fournal of the Royal College of General Practitioners, 1971, 31, 469.

4 Williams, E. I., et al., British Medical fournal, 1972, 3, 445.

Goldberg, E. M., and Neill, J. E., Social Work in General Practice. London, Allen and Unwin, 1972.

${ }^{6}$ Lance, H. Fournal of the Royal College of General Practitioners, 1971, 21,

Suppl. No. 3.
${ }^{7}$ Harte, J. D., fournal of the Royal College of General Practitioners, 1972, 22,612 . 8 Weed, L. L., Medical Records, Medical Education and Patient Care.
Cleveland, Ohio, 1971.

9 Williamson, J. et al., Lancet, 1964, 1, 1117.

10 Lowther, C. P., MacLeod, R. D. M., and Williamson, J., British Medical fournal, 1970, 3, 275.

11 Hodes, C., fournal of the Royal College of General Practitioners, 1968, 15, 286.

12 Forbes, J. A., British Medical fournal, 1969, 2, 46. 